\title{
Influence Of Orthodontic Treatment On Gingival Condition
}

\author{
Irinel Panainte, DMD \\ Department of Orthodontics, Faculty of Dental Medicine, \\ University of Medicine and Pharmacy Tirgu Mures, Romania \\ Ramona Vlad, DMD \\ Monica Monea, Associate Prof., DMD, PhD \\ Department of Osdontology and Oral Pathology, Faculty of Dental Medicine, \\ University of Medicine and Pharmacy Tirgu Mures, Romania
}

doi: 10.19044/esj.2016.v12n21p44 URL:http://dx.doi.org/10.19044/esj.2016.v12n21p44

\begin{abstract}
Aim of the study was to evaluate gingival modifications occuring in patients during orthodontic treatment with fixed appliances. Materials and methods. After inclusion and exclusion criteria were applied, in study were included 60 patients (35 girls and 25 boys). Mean age was 13.1 years for girls and 12.8 years for boys. Treatment period was 19.2 months for the upper arch and 21.3 months for the lower arch. There were taken 2 types of measurements : plaque index (PI) and gingival index (GI), before, during and after treatment. Results. During orthodontic treatment buccal GI was $1.35 \pm$ 0.32 and interpoximal GI was $1.75 \pm 0.25$. PI was $0.85 \pm 0.28$. After the appliances were removed, buccal GI was $1.44 \pm 0.37$, inteproximal GI $1.86 \pm$ 0.22 and PI $1.01 \pm 0.29$. When PI and GI were measured in individual teeth it was found a statistical correlation in the measured values $(\mathrm{p} \leq 0.05)$. Conclusions. Based on these results we conclude that gingival modifications occur during orthodontic treatment. The most important changes are in the lower arch in molar area. After the treatment is finished, the situations come back in normal parameters.
\end{abstract}

Keywords: Orthodontic treatment, plaque index, gingival index, gingival condition

\section{Introduction}

It is well known the fact that the most important factor affecting gingival tissue's health is the bacterial plaque acumulating at the gingival margin (Acharya et al. 2011). In the beginning it appears like a very thin layer but then becomes colonized by a lot of bacteria. Because of this, the 
surrounding structures could be affected easily by the presence of this plaque. If the patient has a very good oral hygiene the effects are neutralized, but when tooth brushing is not done properly, then some problems could occur (Betul et al. 2013). The process of cleaning oral cavity can be influenced by many factors. One of the most important is the aspect of surface. In orthodontic patients can be very difficult to maintain a good oral hygiene because there are a lot of retentive surfaces which sometimes can be very difficult to clean properly (Eser et al. 2011). Although before any orthodontic treatment patients are trained by authorized people to maintain oral care, many times a lot of problems appear. This could be one of the reasons why some authors noticed some gingival modifications in patients with orthodontic appliances. The aim of this study was to observe if there are modifications at the gingival level, using some measurements, in orthodontic patients.

\section{Material and methods}

This study was conducted in the University of Medicine and Pharmacy from Tirgu Mures, Romania. Before starting it, the methodology was analyzed and approved by Ethical Commitee. In the beginning, patients and their parents were informed about all the details of the research, about advantages and disadvantages if they agree to be part of this project, and they signed an informed consent.

In this study 60 patients (35 girls and 25 boys) with ages between 12 and 14 years treated with fixed appliances, MBT prescription, in both dental arches, were included. The mean age was 13.1 years for girls and 12.8 years for boys. The treatment time was 19.2 months for the upper arch and 21.3 months for the lower arch. After the appliances were removed, in the upper arch were placed removable retainers weared during night time and in the lower arch were bonded fixed retainers. A control group was included also in which were included subjects almost same ages but without having an orthodontic treatment.

Two types of measurements were taken: for assessing oral hygiene the plaque index was measured (PI) and for assessing gingival condition the gingival index (GI). The plaque index was assessed with Silness and Loe method. In the study were involved 6 teeth (16, 12, 24, 36, 32 and 44). Each of the four surfaces of the teeth (buccal, lingual, mesial, distal) is given a score from 0 to 3 (table 1). The scores from the four areas of the tooth are added and divided by four in order to give the plaque index for the tooth. For GI there were analyzed two surfaces of the teeth: buccal and interproximal. Then there were given values as in table 2. 


\begin{tabular}{|c|c|c|}
\hline Value & \multicolumn{2}{|r|}{ Meaning } \\
\hline 0 & & No plaque \\
\hline 1 & $\begin{array}{l}\text { A film of plaque adheri } \\
\text { tooth which may }\end{array}$ & $\begin{array}{l}\text { to the free gingival margin and adjacent area of the } \\
\text { seen by using the sample on the tooth surface }\end{array}$ \\
\hline 2 & $\begin{array}{r}\text { Moderate accumulation } \\
\text { and gingival } \mathrm{m}\end{array}$ & $\begin{array}{l}\text { soft deposits within the gingival pocket, or the tooth } \\
\text { gin which may be seen with the naked eye }\end{array}$ \\
\hline 3 & $\begin{array}{l}\text { Abundance of soft mat } \\
\text { Table 1. Silness and }\end{array}$ & $\begin{array}{l}\text { within the gingival pocket and|or on the tooth and } \\
\text { gingival margin } \\
\text { e values for assessing plaque index }\end{array}$ \\
\hline Value & Gingival status & Criteria \\
\hline 0 & Normal gingiva & Natural coral pink gingival with no inflammation \\
\hline 1 & Mild inflammation & $\begin{array}{l}\text { Slight changes in color, slight edema. No bleeding } \\
\text { on probing }\end{array}$ \\
\hline 2 & Moderate inflammation & $\begin{array}{c}\text { Redness, edema and glazing. Bleeding upon } \\
\text { probing }\end{array}$ \\
\hline 3 & Severe inflammation & $\begin{array}{c}\text { Marked redness and edema| ulceration| tendency to } \\
\text { bleed spontaneously }\end{array}$ \\
\hline
\end{tabular}

The measurements were taken at the first appointment before treatment, during treatment, at the end of treatment and during the monitoring period after the treatment was finished. After the data were collected, they were analized and a non-parametric qualitative chi-square test was used for determing the differences between measurements obtained at different time intervals. The value $0.05(\mathrm{p} \leq 0.05)$ was established as a level of statistical significance.

\section{Results}

Overall results show that the gingival condition is modified during treatment time $(1.79 \pm 0.25$ for interproximal region and $1.35 \pm 0.32$ for buccal area), but the highest values are at the moment of removing fixed appliances (1.86 \pm 0.22 for interpoximal and $1.44 \pm 0.37$ for buccal side). The same is for plaque index, lower values during orthodontic therapy (0.85 $\pm 0.28)$ then at the end of active treatment period (1.01 \pm 0.29$)$. Both indices have lower values at the begenning of treatment and in control group also (table 3).

$\begin{array}{cccccc} & \begin{array}{c}\text { At the } \\ \text { beginning }\end{array} & \begin{array}{c}\text { During } \\ \text { treatment }\end{array} & \begin{array}{c}\text { At removal } \\ \text { of appliances }\end{array} & \begin{array}{c}6 \text { months } \\ \text { after } \\ \text { treatment }\end{array} & \begin{array}{c}\text { Control } \\ \text { group }\end{array} \\ \text { GI interproximal } & 0.94 \pm 0.38 & 1.79 \pm 0.25 & 1.86 \pm 0.22 & 0.76 \pm 0.39 & 1.12 \pm 0.36 \\ \text { GI buccal } & 0.53 \pm 0.35 & 1.35 \pm 0.32 & 1.44 \pm 0.37 & 0.41 \pm 0.31 & 0.89 \pm 0.49 \\ \text { PI } & 0.39 \pm 0.30 & 0.85 \pm 0.28 & 1.01 \pm 0.29 & 0.42 \pm 0.46 & 0.57 \pm 0.41\end{array}$

Table 3. Mean values for gingival condition and plaque accumulation (and standard deviation) 
When individual teeth were analyzed, the highest values for both GI (1.91 \pm 0.31 interproximal and $1.72 \pm 0.29$ buccal $)$ and PI $(0.72 \pm 0.51)$ before treatment were noticed in the lower first molar area. The lowest values were observed in upper arch, in the central incisors area (table 4).

Then, PI and GI indices were measured in the same teeth, during treatment time. It was observed that the highest values were again for lower first molar area (2.04 \pm 0.29 interproximal GI and $1.72 \pm 0.29$ buccal GI, $0.80 \pm 0.51$ for PI) and the lower scores were obtained in the upper central incisors region (1.63 \pm 0.26 interproximal GI, $1.18 \pm 0.55$ buccal GI and 0.36 \pm 0.25 for PI). It was found a correlation with statistical significance ( $\mathrm{p} \leq$ 0.05 ) between the values measured in individual teeth during orthodontic treatment time.

TOOTH

16
12
24
36
32
44

16

12

24

32

44

G
INTERPROXIMAI
$1.86 \pm 0.32$
$1.55 \pm 0.43$
$1.84 \pm 0.29$
$1.91 \pm 0.31$
$1.71 \pm 0.35$
$1.85 \pm 0.33$

GINGIVAL INDEX

BUCCAL

$1.68 \pm 0.51$

$1.05 \pm 0.19$

$1.45 \pm 0.57$

$1.72 \pm 0.29$

$1.21 \pm 0.31$

$1.49 \pm 0.38$
PLAQUE INDEX
$0.68 \pm 0.52$
$0.30 \pm 0.37$
$0.40 \pm 0.44$
$0.72 \pm 0.51$
$0.35 \pm 0.29$
$0.39 \pm 0.36$

Table 4. Mean values for the analyzed teeth before treatment (and strandard deviation)

TOOTH

16

12

24

36

32

44

GI
INTERPROXIMA
$1.92 \pm 0.25$
$1.63 \pm 0.26$
$1.86 \pm 0.34$
$2.04 \pm 0.29$
$1.80 \pm 0.54$
$1.89 \pm 0.26$

GINGIVAL INDEX**

BUCCAL

$1.77 \pm 0.54$

$1.18 \pm 0.55$

$1.52 \pm 0.38$

$1.86 \pm 0.60$

$1.33 \pm 0.30$

$1.54 \pm 0.36$

PLAQUE INDEX**

Table 5. Mean values for the individual teeth during treatment (and standard deviation)

**significantly different values for both GI and PI in all analyzed teeth $(p \leq 0.05)$

\section{Discussion}

To maintain a good oral hygiene is very important for the health of periodontium. During the adolescence many conditions can occur to make this process more difficult than it could be for some patients. In some situations the patients are responsible (because they refuse to approach appropiate brushing techniques), but in other cases there are some conditions which do not allow them to do this properly (Batoni et al. 2001, Jordan et al. 2002).One of the most common situations is when a patient presents an orthodontic problem, like dental crowding or skeletal anomalies. It is well known that when crowding is present, sometimes it is almost impossible to do oral cleaning properly. This is one reason why these patients present gingival problems like plaque accumulation or even serious gingival 
conditions (Glans et al. 2003, Katie et al. 2013). To solve these problems, patients should adress to an orthodontic specialist.

Orthodontic treatment has an influence in oral cavity on many levels. Tooth movement means actually bone resorption and apposition, chaning the equilibrium of gingival fibres, and actually changing the entire equilibrium of oral enviorement. There are some changes observed even in bacteria colonization, due to new surfaces of oral appliances used during orthodontic therapy (Sukontapatipark et al. 2001). Some findings confirm that orthodontic pateints present a high risk of enamel demineralization and dental caries (Lovrov et al. 2007). Most of these modifications are due to the fact that orthodontic patients can not or they don't succeed in having a good oral hygiene.

In our study we found that there are some modifications in gingival conditions during treatment time because GI and PI are modified (higher values of these indices than ones before starting treatment), similar findings are in other studies conducted by different reaserchers (Zotti et al. 2011). But in opposition with conclusion from other authors, we found that the most important modifications are right at the moment before removing orthodontic appliances (Julien et al. 2011). The most susceptible part from oral cavity to gingival problems is the molar area (especially in the lower arch) because many authors think that in many patients could be difficult to brush properly (Abboud et al. 2002). Other studies say that the molar area from the upper arch is more sensitive to gingival modifications (Bondemark et al. 2007). When it comes to the less affected region, studies conclude that in incisior area GI and PI have the lowest modifications, since it is easier for patients to mantain a good oral hygiene (Yared et al. 2006, Moreira et al. 2015).

\section{Conclusion}

During orthodontic treatment some modifications of gingival condition can occur. Within the limitation of this study, we can conclude that during the treatment time gingival index and plaque index are higher than before treatment or the ending of this. The most affected area is the molar area in the lower arch and the less affected one is upper central incisors region. After appliances are removed from the teeth there is an important improvement in gingival situation.

\section{References:}

Acharya S, Ashima l, Ashok KU, Utkal M. Effect of three different motivational techniques on oral hygiene and gingival health of patients undergoing multibracketed orthodontics. Angle Orthod 2011; 81:884-888.

Betul R, Al Kawas S. The relationship between dental health behavior, oral hygiene and gingival status of dental students in the United Arab Emirates. 
Eur J Dent. 2013; 7(1): 22-27.

Eser T, Julian SD, Gunsolley JC, Steven JL. Prevalence of white spot lesions during orthodontic treatment with fixed appliances. Angle Orthod 2011; 81(2): 206-210.

Batoni G, Pardini M, Giannotti A, Ota F, Giuca MR, Gabriele M, Campa M, Senesi S. Effect of removable orthodontic appliances on oral colonization by mutans streptococci in children. Eur J Oral Sci. 2001;109:388-392.

Jordan C, LeBlanc DJ. Influences of orthodontic appliances on oral populations of mutans streptococci. Oral Microbiol Immunol. 2002;17:6571.

Katie CJ, Peter HB, Phillip MC. Prevalence of white spot lesion formation during orthodontic treatment. Angle Orthod 2013; 83(4): 641-647.

Glans R, Larsson E, Ogaard B. Longitudinal changes in gingival condition in crowded and noncrowded dentitions subjected to fixed orthodontic treatment. Am J Orthod Dentofacial Orthop. 2003;124:679-682.

Sukontapatipark W, El-Agroudi MA, Selliseth NJ, Thunold K, Selvig KA. Bacterial colonization associated with fixed orthodontic appliances. A scanning electron microscopy study. Eur J Orthod. 2001;23:475-484.

Lovrov S, Hertrich K, Hirschfelder U. Enamel demineralization during fixed orthodontic treatment-incidence and correlation to various oral-hygiene parameters. J Orofac Orthop 2007;68:353-63.

Zotti F, Dalessandri D, Salgarello S, Piancino M, Bonetti S, Visconti L, Paganelli C. Usefulness of an app in improving oral hygiene compliance in adolescent orthodontic patients. Angle Orthod 2011; 86(1) :101-107.

Julien KC, Buschang PH, Campbell PM. Prevalence of white spot lesion formation during orthodontic treatment. Angle Orthod 2011; 83(4): 641-647.

Abboud M, Gruner M, Koeck B. Anterior crowding-just an esthetic problem? J Orofac Orthop 2002;63:264-73.

Bondemark L, Holm A-K, Hansen K, Axelsson S, Mohlin B, Brattstrom V et al. Long-term stability of orthodontic treatment and patient satisfaction. Angle Orthod 2007;77:181-91.

Moreira DM, Oei J, Rawls HR, Wagner J, Chu L, Li Y, Zhang Wa, Whang $\mathrm{K}$. A novel antimicrobial orthodontic band cement with in situ-generated silver nanoparticles. Angle Orthod 2015; 85(2):175-183.

Yared KFG, Zenobio EG, Pacheco W. Periodontal status of mandibular central incisors after orthodontic proclination in adults. Am J Orthod Dentofacial Orthop 2006;130:6.e1-8. 